\title{
Extensive Reading and Writing Reader's Response Journal: The Very Way to Improve Students' English Proficiency
}

\author{
XU Xiao-qin \\ Leshan Normal University, Leshan, China
}

\begin{abstract}
This paper figures out the problems the Chinese students often meet with when they try to obtain the English language ability. In order to assist my students crack down on such problems, I take up the approach of giving them opportunities to play the active roles in English reading activity and requiring them to write reading response journals and to have frequent discussions in the reading class. The approach aims at improving the students' ability and getting them to be trained and improved effectively in the language skills concerned. The approach has come out with remarkable achievements. My understanding is that the process of learning a foreign language is a process indeed of accumulation, including both the language and culture knowledge. The accumulation can be gained by means of reading a lot, thus improving the students' language competence, enlarging their cultural and language field of vision on the western world. We teachers play the function of bridge leading the students to succeed in mastering and applying English as a practical tool in their life and work to come. This paper introduces what I have been trying to assist my students in solving their problems through my teaching practice during the past years.
\end{abstract}

Keywords: communicative competence, extensive reading, reading response journals, language skills

\section{Introduction}

Selected Readings in British Literature is one of the required courses in the English B.A. program, and it is one-semester compulsory course for juniors of English majors at School of Foreign Languages Leshan Normal University. The course focuses on reading influential pieces, looking at the historical events occurring during each era, the life of the authors, and writing papers based on English Literature. The course also provides a sampling of the work of some of the important authors in British Literature. Works are required to be read and examined for an understanding of them at aerial, an appreciation of the literary forms and for the awareness of unifying themes that hold together a culture's conceptual framework. The specific goals are as follows:

(1) Providing the students with a brief outline of the history of British literature up to the first half of the 20th century;

(2) To help the students to appreciate literary language and to consolidate their fluency in English by reading a variety of literary texts;

(3) Introducing students the imaginative use of English and to help them towards an appreciation of literary language and literature;

XU Xiao-qin, professor, Ph.D., School of Foreign Languages, Leshan Normal University. 
(4) Enabling students to explore their own humanity by trying to discover how they react to literary works, and what that reaction says about them;

(5) Grounding students in the literary methods or tools used by British writers;

(6) Strengthening students' ability to read insightfully, to think critically, and to communicate effectively in discussions and writing;

(7) Preparing the students for the study of literature in English at a higher level and to help them develop interest in and, hopefully, the habit of reading extensively;

(8) Consolidating and extending the students' knowledge and fluency in English through interaction with literary texts;

(9) Exploring the "cultural work" of British literature in many forms - including prose, poetry, drama, and visual texts such as film and art;

(10) Enhancing students' understanding of the ways that literature works in particular cultural contexts - that is, why it emerges when it does and what it targets;

(11) Developing the students' ability to recognize and express emotional and moral attitudes on a higher level than about daily occurrences so as to facilitate their communication with educated native speakers.

In order to achieve the teaching goals, the students must do a lot of reading. Only in this way, can they really master the reading skills, enlarge their vocabulary, enhance their sense of language, and improve other language skills. Throughout my teaching experiments on English reading, I focus my interests on incorporating the reading response journals in extensive reading. The result is effective and pleasant. What I stick to do is to make use of English newspapers and magazines, stories and novels, history books and background information, etc., for reading response journals activity to fulfill the content objectives of the course and give the students opportunity to develop skills in reading, speaking, writing, and listening at the same time.

\section{Problems With Reading and Writing}

One hundred and forty-eight students of four classes taking Selected Readings in British Literature Course attend a two-hour course a week in a 17-week semester. Actually they were at a poor level of proficiency in English capacity especially in reading ability, although they are the juniors. Their abilities to use English are very low, unable to listen, speak, read, or write in the proper way. In my literature class, the students usually feel at a loss and encounter many kinds of problems as follows:

(1) Their reading speed is slow. A 500-word reading material takes them over 30 minutes from A to Z. What is more difficult for them is that they are required to answer the reading comprehension quits;

(2) They are not ready with reading skills, such as scanning, skimming, and screening;

(3) The very limited vocabulary building is one of the obvious obstacles on their way of reading comprehension;

(4) They have not acquired the habit of reading a lot.

The reason for all the above mentioned is obvious. The students have been influenced by the traditional or out-of-date English teaching methods still prevailing in most parts of China. At that time of the reading class, a language teacher played the role of dominator. Until now many teachers still do the same thing. Let us take a serous look at what the teacher and the students do in the class. The teacher first reads the reading material for the 
students and then they read it after their teacher. He/She gives a detailed explanation of the new words and phrases, background information about the reading material. Lastly, he/she helps the students understand the reading material and checks the reading comprehension exercises. The whole process of teaching generates no stimulation for students to participate in the reading activity. They just listen to their teacher, take notes, and do the comprehension exercises. The whole class emphasizes words and phrases, with the students focusing on grammatical rules instead of ideas, language fluency, and critical thinking. To conclude, the features of Chinese-English teaching methods go as follows: a concentration on intensive reading as a basis for language study; a preoccupation with the careful, often painstaking examination of grammatical structure and a corresponding lack of attention to more communicative skills; the use of memorization and rote learning as a basic acquisition technique; a strong emphasis on the correction of mistakes, both in written and oral; a view of literature and a reverence for the printed word which tend to the teaching of non-extensive skills; the use of translations as both a teaching and learning strategy; the monolithic examination system in China and the perceived role of the teachers.

\section{Performances With Reading}

In the past few years and as a consequence of the multiple changes and innovations taking place in English language teaching, a great emphasis has been placed on the learner as the main focus of attention. This gives rise to the notion of learner-centered or learner-based curriculum, which differs notably from the traditional curriculum, as it is based primarily on a collaborative process between teachers and learners rather than on a number of rules and norms imposed from outside. I trust many teachers will agree that extensive reading should be a learner-centered curriculum. Extensive reading outside the classroom is a way of language learning through large amounts of reading. As well as facilitating acquisition and learning of vocabulary, it is believed to increase motivation through positive affective benefits.

Proponents such as Krashen (1989) claim that reading alone will increase encounters with unknown words, bringing learning opportunities by inferencing. The learner's encounters with unknown words in specific contexts will allow the learner to infer and thus learn those words' meanings. While the mechanism is commonly accepted as true, its importance in language learning is disputed (Cobb, 2007). The purpose of language teaching is to help students acquire communicative development on that respect. In a broad sense, a person's communicative competence can be summarized as four domains of skills: (1) The learner must attain as high a degree as possible of linguistic competence; (2) The learner must distinguish between the forms he has mastered as part of his linguistic competence, and the communicative functions that they perform; (3) The learner must develop skills and strategies for using language to communicate meanings as effectively as possible in concrete situations; and (4) The learner must become aware of the social meaning of language forms. In Theoretical Bases of Communicative Approaches to Second Language Teaching and Testing (Canale \& Swain, 1980), Canale and Swain elaborate and clarify communicative competence as having three parts: grammatical competence, pragmatic competence, and strategic competence. We have already noted the necessary competences of forming correct sentences/grammar and understanding how social context influences speech (sociolinguistics). The strategic competence involves strategies of avoiding or remedying breakdowns in communication, which are common occurrences in everyday speech. In fact the strategic competence is knowledge of verbal and non-verbal 
communication strategies. They are famous Canale and Swain's Model of Communicative Competence (Canale \& Swain, 1980). These four kinds of competences are inseparable, with grammatical competence the basic one. A solid grasp of grammatical knowledge helps to improve other abilities. Without the ability of the other three, it is difficult to get the meaning across. Hence, language learning should not only include the knowledge of language, but also the ability to use that language. A teacher should offer students opportunities to do a lot of reading. They should read all kinds of authentic language materials, such as newspapers, magazines, science fictions, novels, autobiographies, jokes, detectives stories, and history books, instead of reading their textbooks only.

At the beginning phase, they are required to read easy English readers, which are simple and interesting. Gradually, they are required to read newspapers, journals, English books that available in the library. A list of reading materials for my students' selection is provided. There are some English Reading Reference Materials as following:

Harry Potter and the Goblet of Fire, The Lord of the Rings, To Kill a Mockingbird, Rebecca, The Catcher in the Rye, Great Expectations, Gone with the Wind, Alice's Adventures in Wonderland, David Copperfield, Treasure Island, The Scarlet Letter, The Portrait of a Lady, Martin Eden, The Great Gatsby, The Old Man and the Sea, Robinson Crusoe, Gulliver's Travels, Pride and Prejudice, A Tale of Two Cities, Jane Eyre, Wuthering Heights, Great Expectations, Shanghai Students' Post, 21st Century English, Readers' Digest, Crazy English, English World, and English Study. The students have choices in selecting reading materials. The free selection helps change their attitude toward English reading. They are active in reading activity now. The students are first required to read one article of their own choice from newspapers, magazines, and books each week before the class. All these provide the students as the raw material of the reading response journals. After a semester they are required to read one book each week and the majority of the students can complete the reading task. They are required to keep a record of their reactions, questions, opinions, and comments about the reading material they choose to read before class. In the class, these reading response journals are used for discussion. The reading materials have been proven useful. They provide springboards for lively discussions over social, political, economic, and sports events. Their topics cover as widely as fields like history, science, people, and technology and so on. In the summary section, the students are required to summarize the article in more than 100 words. So the students' reading journals are useful for the teacher.

Before reading becomes a habit, the teacher needs to be able to monitor the students' reading, so that he/she can offer guidance and give encouragement. In the reading class, students read their reading response journals in pairs, groups, or in overall-class discussions respectively. The students can exchange their views and their comments, clarify their understanding of problems, enjoy the knowledge and information they have learned through the reading. While they have discussions, the teacher can check the students' work and the students get feedback from the teacher and their classmates. In the class, there is a special question time/period. The students can ask all kinds of questions. It is the time for the teacher to try his/her best to help the students. More students enjoy sharing their response journals with their peers and discussing their journals in the whole class because they are exposed to a variety of interesting and meaningful topics. The activity gives them a chance to practice their spoken English and listening comprehension. Most of the students feel their understanding is enhanced through writing reading response journals. The emphasis of the communicative approach is on authentic communication, 
as well as the integration of the four skills rather than on grammatical analysis, in the classroom, teaching is student-centered as the core. In the class, there is a special question time/period. In a word, students are encouraged to take risks and to express their ideas in a creative way with "minimum intervention" from the teacher as long as the meaning is expressed clearly. Communicative activities give learners more opportunities to express their own ideas in the classroom and also help learners to integrate the foreign language with their own personality.

\section{Conclusion}

Selected Readings in British Literature is just a one-semester compulsory course for juniors of English majors at School of Foreign Languages Leshan Normal University. One hundred and forty-eight students taking Selected Readings in British Literature Course take part in the teaching experiment, and they participate in a lot of reading activities and writing practice inside and outside the class. They made a rapid progress in reading and writing. TEM-4 (Test for English Majors-Band 4) as the only national standard test for English majors, has been increasingly recognized both at home and abroad in recent years. The certificate of TEM-4 is the most well-received and popular one for English abilities in China. English majors are required to addend the test to prove their English proficiency. The mandated TEM-4 focuses on testing students' language proficiency in listening, reading, and writing. In 2014, all the students took part in the nationwide, standardized English proficiency test-Test for English Majors-Band 4, 95 percent of the students passed the test finally. Most of the students performed well in TEM-4, especially in English reading and writing. I should say they have improved a lot in reading indeed.

As the conclusion to sum up as follows:

(1) Extensive reading opens up a whole new world, enabling students to learn about different people, their cultures, traditions, customs, outlooks, and the reasons why they behave in certain ways;

(2) Skills learned through extensive reading are transferred to other areas of the language, such as writing, speaking, and listening;

(3) Extensive reading allows for students to different registers of the target language that they will meet in varied contexts;

(4) Students build up and increase vocabulary through extensive reading, very important for effective communication;

(5) By means of reading response journals in extensive reading, students have the chance to read and write on topics they are interested in before they have a discussion in class. The activity helps improve the students' writing skills and train them to express themselves;

(6) Thinking in English is the foundation of expressing oneself in English. To achieve this, keep a habit of reading is one of the most effective pathways.

As a working language in the fields of international finance, trade, industry, information technology, and so on, English is playing a more important role than ever before in international communication. English is a worldwide as well as a science research language. English is one of the most indispensable tools in the 21st century. English is the dominant language of international communication and with increasing globalization, it is important to have a refined understanding of the nature and structure of English and how we communicate with 
each other. Reading extensively and writing reader's response journal should be the universal channel and the very way to improve students' English proficiency.

\section{References}

Bell, T. (1998). Extensive reading: Why? and how? The Internet TESL Journal, IV(12).

Canale, M., \& Swain, M. (1980). Theoretical bases of communicative approaches to second language teaching and testing. Applied Linguistics, 1(1), 1-47.

Cobb, T. (2007). Computing the vocabulary demands of L2 reading. Language Learning \& Technology, 11(3), 38-63.

Harmer, J. (1983). The practice of English language teaching. London: Longman Group Ltd..

Howatt, A. P. R. (1997). A history of English language teaching (6th impression). Oxford, UK: Oxford University Press.

Krashen, S. (1989). We acquire vocabulary and spelling by reading: Additional evidence for the input hypothesis. The Modern Language Journal, 73(4), 440-464.

Littlewood, W. (1981). Communicative language teaching: An introduction. Combridge: Combridge University Press. 